\title{
La acción como elemento determinante de los cambios ${ }^{1}$
}

\author{
Paulina Muñoz Medina*
}

\begin{abstract}
Resumen
El escrito presenta una síntesis del ensayo que logró el premio del jurado en el Concurso de Ensayos de Sociología Nelson Gutiérrez en 2010. Por lo cual, se rescata el análisis de la matriz sociopolítica que pone en discusión a dos investigadores nacionales, y se abordan las relaciones de sus componentes: Estado, Sistema de Representación y Sociedad Civil. La categoría de matriz se aplica a nivel político poniendo énfasis en la estructura y la acción para así revisar la interdependencia y autonomía de los cambios estructurales ocurridos en Chile durante el siglo XX.

Palabras clave: Matriz Sociopolítica, Estructura, Acción

Abstract

The article portrays a succinct account of the essay that was awarded the Prize in the Nelson Gutierrez Sociology Essay Contest in 2010. Therefore, it recaptures the analysis of the socio-political matrix which gathers two national researchers together who discuss the relationship of its components: State, Representation System and Civil Society.

The matrix category applies to the political level with an emphasis on the structure and the action in order to review the interdependence as well as the autonomy of the structural changes that occurred in Chile during the twentieth century.
\end{abstract}

Keywords: Socio-political Matrix, Structure, Action.

\footnotetext{
1 El presente escrito es un resumen del ensayo presentado por la autora al concurso Premio Nelson Gutiérrez de ensayos de Sociología. Para salvaguardar los criterios de formato de Revista Temas Sociológicos, el original debió ser editado, dicha actividad estuvo a cargo del Dr. Nicolás Gómez.

* Alumna de la Carrera de Sociología de la Universidad Católica Silva Henríquez, paulinamxm@gmail.com
} 


\section{Introducción}

El presente ensayo revisa los procesos políticos acaecidos durante el siglo XX en Chile, suponiéndolos como expresiones de cambios estructurales de la sociedad. Para esto se hace una revisión de los planteamientos de Mascareño (2010) que abordan la concepción de Matriz Sociopolítica y describen las relaciones entre Estado, Sistema de Representación Política y Sociedad Civil. También se utiliza el ejercicio hecho por Salazar y Pinto (1999) y Moulian (2009).

En detalle, la noción de matriz sociopolítica se utiliza en el caso del Partido Radical, en la forma de explicar su origen y transformaciones que acontecen a la par de un aumento en la autonomía de los ciudadanos a causa de su entrada a los registros electorales. Luego se destaca el período del quiebre en las estructuras de los gobiernos de la Coalición de Centro Izquierda, el término de muchos movimientos sociales que se venían desarrollando con fuerza desde las primeras décadas del siglo $\mathrm{XX}$.

A través de la reflexión de estos procesos de transformaciones estructurales se intenta describir cómo se vivieron los cambios en la ciudadanía, especialmente en la formación de movimientos sociales populares que se destacan por la búsqueda de autonomía para motivar la acción organizada del pueblo.

\section{La matriz sociopolítica y los componentes que la integran}

Para analizar los cambios sociales en Chile como variaciones de la estructura política, Mascareño, citando a Garretón, introduce el concepto de matriz sociopolítica. Esta categoría es situada por Mascareño como una teoría de alcance intermedio porque permi- 
te estudiar las particularidades de los distintos elementos de la estructura social y sus relaciones ${ }^{2}$.

(La matriz sociopolítica) define las relaciones entre el Estado y sus diferentes dimensiones (unidad nacional, relaciones de dominación, agentes de desarrollo e integración), el sistema de representación (instituciones y el sistema de partidos) y la base cultural y socioeconómica de los actores sociales (sociedad civil y economía) (Garretón, 1997, Apud. Mascareño, 2010: 125).

A continuación buscamos reflexionar sobre la relación de los componentes de la matriz asumiendo que la acción individual o colectiva moviliza a las estructuras, lo que puede llevar a determinar la interdependencia entre ellas y, en otras ocasiones, a su autonomía (Mascareño, 2010: 130).

Para saber cuándo ocurre una situación o cuándo ocurre la otra, hay que entender que el actor moviliza la estructura cuando es capaz de cambiarla y la reproduce cuando, siendo sujeto, lleva a cabo actividades dentro de sus determinaciones. En la primera, el individuo se comprende como actor y, en la segunda, el mismo individuo se interpreta como sujeto. De esta forma y tomando ambas situaciones, el individuo o la colectividad quedarían determinados como "actor-sujeto" (Garretón, 2000, Apud. Mascareño, 2010:130), movilizándose en direcciones marcadas.

Así en la primera hay autonomía de los actores porque el actor-sujeto apela a principios de modificación y, por dicho proceso, moviliza la acción con la pretensión de generar cambios en las estructuras. Mientras que en la segunda situación se genera interdependencia por parte de los actores, debido a que estos

\footnotetext{
2 "Esta teoría sociológica de alcance intermedio es desarrollada totalmente en término de los elementos de la estructura social, más que para proporcionar descripciones históricas concretas de sistemas sociales particulares. Así, la teoría de alcance intermedio nos permite trascender el falso problema de un conflicto teórico entre lo nomotético y lo idiotético, entre lo general y lo totalmente particular, entre la teoría sociológica generalizadora y el historicismo" (Merton, 1968: 61).
} 
solicitan principios que aseguren la mantención de las estructuras pretendiendo la movilización dentro y/o en torno a ellas.

Sin embargo, Garretón considera que la acción genera la interdependencia entre los componentes a partir de tres principios que mantienen los portadores de la acción, en tanto "apelan a principios de estructuración, conservación o cambio de la sociedad" (Garretón, 2000, Apud. Mascareño, 2010: 131). El hecho de que a través de la acción se movilizan instancias para cambiar aspectos de la estructura explicando lo que sucede con la autonomía de la acción, se explicaría por la pérdida de autonomía de la estructura, dejándose subordinar por la acción en momento de movilización.

Y aunque por medio de la acción se logren modificaciones o cambios, la estructura tendría, aun cuando subordinada en el proceso de cambio, la probabilidad de retomar su funcionamiento una vez definidas las transformaciones.

Ahora también, existe otro aspecto para analizar la relación. A Garretón le interesó entender la diferencia que existía entre la autonomía de la acción y la autonomía de la estructura, considerando que la diferencia se genera por una temporalidad distinta para cada una de ellas. De esta forma se explica que la estructura opera en la sociedad con una temporalidad que ocurre en momentos, mientras que la temporalidad de la acción es continua y evolutiva (Mascareño, 2010:140). La estructura evoluciona a través de la movilización de la acción. En cambio, la acción tiene que evolucionar por sí misma.

\section{Conformación del Partido Radical como estructura del Sistema de Representación}

El Partido Radical chileno se funda en principios opuestos al autoritarismo, liberalismo y en contra del centralismo mercantil de Santiago que bloqueaba el desarrollo capitalista de las provincias. Por tanto, emerge en oposición a la oligarquía y el autoritarismo de Montt y Varas, siendo ellos representantes de las tendencias 
conservadoras; y también se oponen al Partido Liberal que se había unido al Partido Conservador.

Los radicales pensaban la descentralización de la economía mercantil, pretendían promover un gobierno en el cual se descentralizaría el Estado y aspiraban a la comuna autónoma. Por otro lado, esperaban conseguir la laicización de la educación pública (Salazar y Pinto, 1999).

El radicalismo logró organizarse incorporando a los empresarios de la minería del Norte Chico de Chile, a los artesanos y profesionales. Sin embargo, "la economía agrícola y minera del norte chico colapsó irreversiblemente después de la crisis de 1873" (Salazar y Pinto, 1999: 235), permitiendo que muchos de los constituyentes del partido lo abandonaran y engrosaran otras expresiones políticas.

En reemplazo del empresariado minero y agrícola del Norte Chico, entran al Partido Radical grupos terratenientes que eran "de tipo capitalista, surgido en la huella de la 'pacificación' de la Araucanía, grupo que se hizo fuerte después de 1885" (Salazar y Pinto, 1999: 235-236), mientras que los grupos de artesanos, siendo anteriormente una de las bases del Partido Radical, emigraron hacia el Partido Democrático y otras divisiones de tendencias socialistas.

Entonces el Partido Radical queda conformado por un grupo de terratenientes modernos, liberales y capitalistas, también por la clase media urbana de Santiago, personas provenientes de Atacama, Coquimbo, Concepción, Antofagasta y Tarapacá y, a pesar de esta heterogeneidad, "el ideologismo del Partido Radical resultó temible para todos sus adversarios políticos" (Salazar y Pinto, 1999: 236).

Por causa de los cambios que se gestaban en su interior "el Partido Radical no tuvo reparos en evolucionar con el tiempo y en renunciar a buena parte de su identidad política" (Salazar y Pinto, 1999: 237). Aquí, su base estructural hace posible tolerar 
modificaciones que lo llevarán a acercarse a nuevos ideales sociales, sobreviviendo a las nuevas tendencias del electorado que había comenzado a cambiar debido a las tendencias de los nuevos grupos de inquilinos con derecho a voto seducidos por los ideales revolucionarios que hacían presencia en localidades de mayor población obrera y ante las complejidades que se vivieron en la época parlamentaria: "las protestas nacionales desnudaron la crisis de representación de la clase política y la crisis de legitimidad del Estado" (Salazar y Pinto, 1999: 41).

En esta aventura por las necesidades de avance en la sociedad, el Partido Radical expresa su adaptación al medio, en la medida que no ve solución de mantenerse vigente en concordancia con la masa ciudadana desde los partidos de derecha; y porque modificó sus bases ideológicas a las demandas persistentes de las localidades mineras o agrícolas.

Premunidos de este nuevo norte los radicales abandonaron sus cargos en el segundo Gobierno Liberal de Arturo Alessandri y firmaron, en 1936, el pacto del Frente Popular con los emergentes Partidos Socialistas y Comunistas (Salazar y Pinto, 1999: 238).

Entonces, la transformación ocurre respecto a la identidad originaria, es allí donde acontece el movimiento de la acción, la cual tomó su poder de autonomía para adaptarse a una sociedad con aspiraciones.

Esto es analizable desde una lógica interna de observación, puesto que si se hace el ejercicio desde una lógica externa, la acción y la estructura se movilizan porque dependen de los cambios de la ciudadanía. En este último punto ocurre una interdependencia entre el Partido (sistema de representación) y los actores sociales que votaban (la sociedad civil).

Aun así, la adaptación no pretendía esencialmente comprender la crisis social desde el punto de vista de quienes lo enfrentaban originalmente; más bien, esto era un modo de entrar en el mundo interno de los afectados por sus carencias y, así, conseguir 
adhesión al Partido. Esto no fue del todo ignorado por las personas que se venían integrando a los registros de electores, pues las masas populares que aumentaban en los registros no beneficiaron precisamente al Partido Radical, sino que se fueron acercando cada vez más hacia el socialismo.

(El Partido Radical) habiendo obtenido un veinticinco por ciento promedio, para el período 1918-1925, bajó a un diecinueve por ciento promedio para el período 1932-1949 (Salazar y Pinto, 1999: 239).

A pesar de aquel descenso en el momento que transcurría su participación política en el gobierno, constó con tres períodos en los que fueron desarrollando sus programas e incorporando sus ideales. Es así que los objetivos de gobierno de la Coalición de Izquierda entre 1938-1952, fueron la industrialización promovida por un Estado Intervencionista-Desarrollista y la democratización.

La Coalición de Centro-izquierda actúa como un sujeto autónomo desde su proyecto político, no pretendiendo situarse como mediador de las clases dominantes. La autonomía que prevalecía para la coalición significaba que tenían una lógica propia para sus reformas modernizantes: una ligada a un componente mesocrático y otra a un componente popular. Lo que se fundamentaba en la necesidad de "una revolución democrático-burguesa" como etapa previa al socialismo.

Antes de llegar a esta etapa, el objetivo del sector era el desarrollo económico al estilo burgués, quizás para lograr financiar el desarrollo de las sociedades en aspectos determinantes como la educación y la salud. Sin embargo, el intervencionismo estatal en este proyecto era sinónimo de bloquear en alta medida la iniciativa privada.

Esto determina una confusión de dos estructuras que se contraponen en la realidad, aun cuando se busque mezclarlas para formar un sistema mixto en la economía. Por un lado, se tiene un sistema intervencionista para llevar a cabo las políticas económicas del país, donde el Estado es quien las maneja y, por otro lado, 
se cuenta con un sistema económico de mercado donde las políticas que se dictan serán determinantes para el libre mercado.

En esto se contrapone la estatización de las empresas y su privatización, y su combinación resulta contraproducente porque está el sentido ideológico de cada una de estas estructuras, debido a que tienen distintas fórmulas para desarrollarse como tal. Por ejemplo, en torno al manejo de las empresas y de cómo construir una sociedad individualizada o colectiva.

Por lo tanto, ambos sistemas están muy definidos, por lo que una de las estructuras buscará subordinar a la otra para ganar más espacio. El conflicto ocurre y redunda en el no desarrollo de sus autonomías, por tener bases contradictorias una de la otra.

En términos de la noción de matriz sociopolítica, el conflicto ocurre entre el componente del Estado y el de la sociedad civil. En este último, los actores que se mueven en la economía chocan por principios ideológicos, y buscan determinar la autonomía de cada uno e imponerse.

Entre los componentes que se diferencian se da también una situación de interdependencia, específicamente entre el sistema político y el sistema económico ${ }^{3}$. Este último debe disponerse a los proyectos que determine la organización que maneja el Estado. Pero si el sistema económico que se impulsaba para llevar a cabo la estrategia desarrollista desde la industrialización, no lograba ser compatible con las políticas que se buscaba impulsar, tendría que haber existido una salida a un nuevo modelo económico acorde con el objetivo de gobierno.

En otro sentido, al articular la estructura, el gobierno dispone de dos contextos de desempeño para la acción, lo cual favorece la

\footnotetext{
3 “La democratización paralela a la industrialización y el papel decisivo del Estado, restringieron algunos espacios de la iniciativa privada y redujeron las posibilidades para que las lógicas de la acumulación privada primaran, sin contrapesos, sobre las lógicas redistributivas o de democratización de oportunidades." (Moulian, 2009: 33)
} 
conformación de los actores-sujetos. Por ejemplo, para haber desarrollado las estructuras definidas como programas de gobierno de la Coalición de Izquierda (1938-1952), de acuerdo a una acción o a varias, se debían hacer cambios radicales en la Constitución de 1925; esto hubiese mostrado la autonomía de los actores para lograr la estructura o, visto de otro modo, la estructura hubiese quedado subordinada a la acción de actores que alentaron el cambio. Sin embargo, lo que sucedió durante el periodo fue la adaptación del gobierno, la cual permite el programa de la Coalición de Izquierda ${ }^{4}$.

Por tanto, la interdependencia se da por razones estructurales donde se requiere de acuerdos sobre principios que motivan la acción, y los portadores de acción se movilizan para generar acuerdos para mantener las funciones del gobierno en relación a sus programas, y no llegar a producir relaciones de componentes que diluyan la normatividad acordada, lo cual depende de los principios ideológicos que instituyen la sociedad. ${ }^{5}$

\section{Cambio estructural a partir de la instauración del Régimen Militar}

Tal es el caso del Régimen Militar, donde la acción de la sociedad civil y la clase política civil pierde autonomía porque no es capaz

\footnotetext{
4 “[ ] los partidos electoralmente dominantes del período de 1938-1973 (el Radical y el Demócrata-Cristiano) trazaron una trayectoria similar: ambos flotaron sobre la opinión sufragista de una masa ciudadana en trámite de emancipación electoral, y lideraron la instalación del Estado Desarrollista y Populista sin reformar la Constitución de 1925" (Salazar y Pinto, 1999: 241).

5 También se está expuesto a que la sociedad civil, sobre todo la masa ciudadana que sufraga en elecciones, mantenga sus preferencias por algún partido político. En este caso los que integran el gobierno (representando al Estado) tendrán que llegar a acuerdos con los ciudadanos que votan para ser elegidos por ellos en la mayor cantidad de elecciones posibles con tal de mantenerse en el poder estatal. En esto cabe la promoción de programas antes de llegar a las votaciones, es decir, que el movimiento de los portadores de la acción se sustente en la promoción de las ideas de los partidos que se presentan para tales elecciones.
} 
de mover las estructuras para generar un cambio en ellas. A diferencia de esto, mirándolo desde el plano contrario, cuando la Constitución de 1980 se establece como tal, se observa la acción subordinando a la estructura. De esta forma, la acción desarrolla su poder de autonomía.

La interdependencia ocurre porque para que el Régimen Militar (observándolo como componente del Estado) pueda mantenerse y llevar a efecto sus funciones, tuvo que bloquear sectores de la matriz sociopolítica. Así, las nuevas gestiones del Régimen Militar serían las que impulsan el desarrollo del capitalismo de una forma muy distinta al que existió dentro del Estado EstatistaDesarrollista (1938 a 1973).

Este nuevo sistema se puede observar, desde Salazar y Pinto (1999), como una revolución y como una contrarrevolución. La primera se refiere a un plano económico donde se produjo la revolución capitalista, impulsando una nueva economía chilena -a pesar de que ya habían existido indicios de este tipo de estructuras entre fines del siglo XIX y comienzos del siglo XX.

El sistema neoliberal que se comenzaba a implantar traía novedades modernizantes que buscaban el éxito de este sistema. Por ejemplo, respecto a la privatización de una gran cantidad de empresas que antes habían permanecido sujetas al Estado. Y también por las tecnologías que se iban instalando para acrecentar las producciones (Salazar y Pinto, 1999: 101).

Respecto a la contrarrevolución, la misma se expresa en las estructuras porque "en el corto plazo, fue anti-proletaria, y en el mediano, pro-capitalismo internacional" (Salazar y Pinto, 1999: 101). Entonces, fracturó las estrategias de las políticas desarrollistas del Estado y se provocó represiones de las organizaciones de trabajadores, limitando la participación activa de los ciudadanos en la política.

Más allá de las connotaciones que se le atribuyan a los cambios que surgieron con aquellos sucesos, lo que sí es seguro es 
que en la implantación de este nuevo orden autoritario se fundan las bases para la creación de un nuevo empresariado, una nueva burocracia, una nueva sociedad civil.

Así, la Constitución de 1980 fija la instrumentalización de la clase política civil y, a través de ésta, la de los ciudadanos. Gabriel Salazar aclara que tal Constitución "está estructurada para asegurar el orden interior (o sea, la gobernabilidad de la sociedad) y la reproductibilidad formal del sistema institucional" (Salazar y Pinto, 1999: 104), procurando mantener la administración de los organismos del Estado antes de procurar el desarrollo político de la sociedad civil.

Para asegurar aquel orden legitima organismos que contribuyen a la tarea del gobierno. "La constitución concede a las Fuerzas Armadas, de modo explícito, el rol de garantizar el orden institucional de la República" (Salazar y Pinto, 1999: 105), algo que corrompería aquel orden sería el generar actividades políticas fuera de los partidos políticos, es decir, realizar acción política en forma autónoma, esto iría en contra del orden público y la seguridad del Estado, de modo tal que sería nombrado como una acción inconstitucional, la que bajo las normas legales para la Constitución de 1980, podría ser castigado con la pérdida de la ciudadanía (Salazar y Pinto, 1999). Los ciudadanos sólo quedan con ciertas atribuciones en lo referente a la política, es decir que el ciudadano chileno queda con "solo dos (estrechos) canales constitucionales: el 'deber' de votar, y la 'posibilidad' de peticionar" (Salazar y Pinto, 1999:108).

Para hacer factible estas decisiones en la legislación se crean leyes que bloquearán cualquier conducta contraria a la necesaria para el desarrollo de la Constitución, es por eso que referido a la búsqueda de aquella protección, Salazar menciona la "lógica de la seguridad que, a fin de cuentas, es una gran operación de pinzas para atenazar a toda la masa ciudadana" (Salazar, 1999:106), dejándola inamovible para muchas acciones autónomas que pudiesen lograr su desarrollo político y, desde este, un mejor avance social. 
Así queda de manifiesto en el Artículo 23 de la Constitución de 1980: "Los grupos intermedios de la comunidad y sus dirigentes que hagan mal uso de la autonomía que la Constitución les reconoce, interviniendo indebidamente en actividades ajenas a sus fines específicos, serán sancionados en conformidad a la ley" (citado en Salazar y Pinto 1999: 108).

Al hablar del "mal uso de la autonomía", la misma se la considera como una acción de violencia porque atenta contra lo normado. Esto se puede presentar en casos como las movilizaciones porque, en la mayoría de las veces, no están autorizadas y se las considera como promotoras de la ruptura del orden público, independientemente de la causa que se trate (esto puede ser alzas de impuestos, precios, por problemas en el sistema de salud o educación).

Tal realidad considerada como violencia porque es ejercida por la masa ciudadana, se observaría diferente si fuera llevada a cabo desde los organismos que están autorizados, es decir: "En cuanto al uso de la violencia, como método de acción política contra o en defensa del régimen constitucional, está permitido (implícitamente) sólo a las fuerzas de seguridad y de orden" (Salazar y Pinto, 1999: 107).

\section{Análisis del movimiento social como acción de la sociedad civil}

Las movilizaciones populares nacen desde una experiencia bien definida que ha sido continua en la historia, aquella experiencia corresponde a sujetos en condición pobre que se manifiestan en acciones de lucha. Y el otro elemento que impulsa la acción corresponde a la dominación por parte de las élites con mayor poder económico y político.

En palabras de Salazar, "la dominación viola la condición innata de todo sujeto, la búsqueda de su autonomía. Producto de ello el movimiento social popular reacciona, luchando en contra 
de la subordinación, resistiéndola de diversas maneras, algunas visibles y otras no tanto" (Salazar y Pinto, 1999: 98).

Así, los movilizados ${ }^{6}$ son sujetos que se mueven en la historia para lograr objetivos en común, son sujetos porque habitan en una estructura, teniendo igualmente la facultad (cuando es permitida) de modificarla o cambiarla para luego seguir moviéndose.

Sin embargo, los movimientos estaban marcados en sus inicios por la violencia popular. Esto tenía sus orígenes por efecto de las malas condiciones de vida y laborales que enfrentaba el bajo pueblo, lo que provocaba tensiones entre ellos mismos, causando en situaciones de revueltas, situaciones de violencia, las que se podían ir agudizando (Salazar y Pinto, 1999: 113).

Con el correr de las décadas aquella expresión se va encauzando hasta formar organizaciones de trabajadores con ideologías definidas, las que les permitió objetivar sus acciones, clarificando el norte que perseguirían al ordenar las demandas para exigirlas. Así, "la cohesión interna de las primeras organizaciones de trabajadores se fundó sobre tres pilares: el impacto organizativo del capital; el discurso ideológico de izquierda; y la experiencia solidaria proveniente de las comunidades de origen del trabajador. Aquí están las bases del moderno movimiento sindical" (Salazar y Pinto, 1999: 114).

La clase obrera, desde sus orígenes, ha manifestado sus necesidades más básicas esperando satisfacerlas en el corto plazo en lo posible. Ante esto, se contrapone la idea de instaurar un régimen o un plan de gobierno socialista, puesto que requeriría de un proceso donde el obrero y sus familias concientizaran el

6 "[] el concepto alude a movimiento, acción, actividad, supone que los actores históricos (en este caso, los sujetos populares) se movilizan con el objeto de transformar una realidad considerada adversa o, por lo menos, problemática." (Salazar y Pinto, 1999: 97) 
significado de una revolución, sobre todo si ésta tuviera éxito. Ya que la mantención de una sociedad de ese tipo requeriría un segundo esfuerzo ciudadano.

De esto resalta que los trabajadores más carentes y también de las clases medias, más allá de incorporarse a un partido político o movimiento ideológico de luchar por sus demandas, estarán más interesado por suplir lo antes posible esas necesidades y, por tanto, pretenderían acercarse al líder que se proponga satisfacérselas a la brevedad.

Un ejemplo de esto son las agrupaciones de pobladores que se reunían para crear un sistema que les permitiera conseguir una vivienda "cuando el alquiler dejó de ser la principal forma de acceso a la vivienda, el movimiento poblacional presionó por leyes que facilitaran la compra de casas y el término de las irregularidades en los procesos de loteo" (Salazar y Pinto, 1999: 127).

Esta fue una de las demandas más importantes, la que no fue atendida satisfactoriamente por las autoridades públicas, por la misma razón se hacen presentes las movilizaciones a cuenta de generar presión. Para incrementar aún más estos movimientos y conseguir mejores resultados, los pobladores "se agruparon en torno a las ligas de arrendatarios, y obtuvieron del Gobierno la formación de tribunales de la vivienda donde los miembros de las ligas tenían representación" (Salazar y Pinto, 1999: 127).

\section{Transición entre los periodos de gobiernos de la Concertación y la Derecha}

En el contexto de los gobiernos Concertacionistas en el manejo del Estado, estos mantuvieron una relación de interdependencia con el cuerpo normativo de leyes provenientes desde el Régimen Militar. De esta forma, cada gobierno fue un instrumento de la Constitución de 1980, en la medida que existió una relación de estructuras. Por un lado, la estructura constitucional dependien- 
te de cada movimiento de los programas de los gobiernos de la Concertación y que estuvieron dentro del marco establecido con tal de no perder la estructuración de sus bases. El principio que se le atribuye a la movilización de la acción es el de la conservación de la estructura normativa.

Esto se expresa cuando se hablaba de la pérdida de la autonomía de la sociedad civil, es decir, de los actores sociales que la integran, tales como los que participan en la economía, en elecciones populares, la masa ciudadana. La marginación de esta responsabilidad de reflexionar acerca de las políticas, pasa a ser una maniobra para que otros organismos sí autorizados pero delimitados a la vez, puedan ejercer tales responsabilidades.

Por otro lado, existe una relación de interdependencia entre la ciudadanía y el cuerpo normativo. En este último están establecidas las leyes que determinaron la forma de participación política de la clase civil. Por tanto, se produjo una participación pasiva que provocó una distancia del pueblo hacia el plano político. Mientras que tal pueblo se mantiene como instrumento de la base estructural subordinado a las decisiones políticas.

En consecuencia, se observa al individuo siendo más sujeto que actor, lo cual se debe a la pérdida legitimada de la participación en la política. Sin embargo, el actor se rescata cuando entra en movilización, aun cuando éstas sean reprimidas. Esto se observa en las huelgas de distintas organizaciones: estudiantiles, organismos de salud, trabajadores, transporte y en las diferentes movilizaciones de la acción que sucedieron en el periodo de la Concertación.

Estas acciones de la ciudadanía han generado negociaciones con las autoridades políticas, incluidas las del sector empresarial. Dicho de otro modo, una relación entre componentes de la matriz sociopolítica, a saber: Estado y Sociedad Civil. Pero la negociación no genera específicamente una modificación en la estructura política, sino que el desarrollo de la adaptación de un programa donde las partes están conformes con el orden habitual. 
Así, el carácter de la Concertación se manifiesta como subordinado al cuerpo normativo, dejando ver una relación de interdependencia, o sea, los gobiernos desarrollan programas políticos que se adaptan a las estructuras buscando un consenso con la sociedad civil.

Por su parte, la derecha ha ido construyéndose y ampliándose en el período de la Concertación, especialmente porque tiene espacio para su acción en la Cámara del Senado, aprobando o no leyes y programas.

En este caso, nuevamente, hay una relación de interdependencia que se genera entre el Estado y los representantes políticos que participan en las decisiones normativas que se esperan llevar a cabo desde un componente $u$ otro, lo que hace entender la dificultad para la acción autónoma que pudiese alcanzar el sistema político si tuviera, por lo menos, una facultad de llevar a cabo diseños o programas sociales que ya han sido calculados antes de que un gobierno en particular se establezca en el poder durante un período determinado.

La espera del pueblo, en general, de acceder a proyectos sociales no depende precisamente de la única posibilidad de participación en la política que estos actores tienen (refiriéndose a la población inscrita en los registros electorales), sino que este proceso es un mero trámite instrumental para que las élites políticas que han llegado a gobernar (abordando específicamente este período de transición), lleguen al poder y se mantengan. Es decir, que la espera por proyectos sociales depende del acuerdo que exista entre los organismos políticos autorizados para cumplir el rol de aprobar o desaprobar un proyecto de ley. Y del principio ideológico que mantenga cada sector político.

\section{Conclusión}

Este ensayo ha descrito las características de las estructuras de sistemas constituyentes: políticos y económicos, a través del elemento 
"acción", pudiéndose constatar los principios determinantes para la conformación de las estructuras sociales de los hechos revisados. Tales principios buscan cambios, conservación o estructuración de la matriz y de lo social, y mueven a los portadores de acción.

Por lo que al revisar los acontecimientos históricos se pudo identificar cuándo, a través de la acción, se determinan modificaciones en las estructuras o cuándo se genera un mantenimiento, observando los cambios parciales, radicales o, incluso, totales en la sociedad chilena.

También ha sido posible reconocer principios en la determinación del movimiento de la acción entre componentes de la matriz sociopolítica y, también, cambios de la acción que especifican los sistemas y las estructuras sociales.

Ahora bien, para propender a una sociedad en dirección a las nuevas estructuras impuestas se necesitaría una sociedad en contacto con las políticas sociales que establecen los organismos estatales, debido a que se observa un alejamiento hacia el plano político además de la imposibilidad de autonomía y restricciones que se dejó por escrito en las nuevas normas constitucionales hacia el ejercicio político.

Para los actores sociales existe plena libertad de decidir qué hacer para ganar espacio en el ambiente social; para esto tienen varias posibilidades que les ha otorgado la estructura constitucional. Sin embargo, las fallas funcionales están en la determinación de las políticas, por lo que la autonomía debe tener amplio espacio para involucrar a los ciudadanos y lograr un desarrollo local en la sociedad.

\section{Bibliografía}

Mascareño, Aldo (2010): Diferenciación y Contingencia en América Latina, Santiago, Universidad Alberto Hurtado.

Merton, Robert (1968): Teoría y Estructuras Sociales, México D.F. Fondo de Cultura Económica. 
Moulian, Tomás (2009): Contradicciones del Desarrollo Político Chileno 1920-1990. Santiago, LOM.

Salazar, Gabriel y Pinto, Julio (1999): Historia Contemporánea de Chile I, Estado, Legitimidad, Ciudadanía, Santiago, LOM.

Salazar, Gabriel y Pinto, Julio 1999): Historia Contemporánea de Chile II, Actores, Identidad y Movimiento, Santiago, LOM. 